\title{
The use of natural resources to improve household income, health, and nutrition within the forests of Kianjavato, Madagascar
}

\author{
Cortni Borgerson', I,III, Steig E. Johnson'1, Edward E. \\ Louisv, Sheila M. Holmes'v, Evelin Jean Gasta \\ Anjaranirina", Hervet J. Randriamady", Christopher D. \\ Golden!,II,VI
}

\author{
Correspondence: \\ Christopher D. Golden \\ Harvard T.H. Chan School of Public Health \\ Department of Environmental Health \\ 401 Park Drive \\ Boston, MA 02115, USA \\ Email: golden@hsph.harvard.edu
}

\begin{abstract}
Understanding natural resource extraction in Madagascar is key to developing wider conservation and management strategies that ensure the continued delivery of essential ecosystem services, and the development of health and economic strategies to meet the demands of a growing human population. In the Kianjavato lowland rainforest of southeastern Madagascar, $78 \%$ of lemur species, $83 \%$ of native carnivoran species, and $67 \%$ of frugivorous bat species are threatened with extinction. All three of these groups of mammals are commonly hunted for food in other regions of Madagascar, yet we knew little about current levels of hunting or whether the use of forest resources significantly affects human welfare in this region. We used health assessments of 1267 Kianjavato residents and semi-structured interviews of members of 336 households in 17 communities in Kianjavato to investigate human-environmental interactions. We found high prevalence of child and teenage malnutrition. More than half of the population under 20 years old was stunted, more than half was underweight, and more than one fifth was wasted. Further, one in six residents were anemic. We found that Kianjavato's forests provided essential ecosystem services for its rural communities. As Kianjavato's forests are altered to meet the needs of a growing human population, these direct-use ecosystem services (such as the use of wild animals for food or plants for medicine) are unable to similarly expand to meet the basic needs of the families living in these forests. A worrying proportion of the Kianjavato population depends on forests to meet their healthcare, nutritional, and economic needs, yet they may be failing to do so. All surveyed households (100\%) depended on forests to meet their healthcare needs and $40 \%$ of the regional economy involved the extraction of finite forest resources (i.e., precious stones). Most
\end{abstract}

households consumed very little wildlife (two animals per household per year) and the great majority (83\%) of the forest animals they ate were not threatened with extinction. Forty percent of wildlife were caught illegally. Although hunting is likely not imperiling local wildlife at present, $16 \%$ of the Kianjavato population hunts wildlife and $20 \%$ are malnourished. The ecosystem services of Kianjavato's forests may currently be insufficient to meet the needs of residents. Therefore, targeted efforts to increase local access to the healthcare system and to improve household nutrition and economy by improving the production and stability of local agricultural products may increase the long-term sustainability of wildlife hunting, household incomes, and regional food security. Efforts such as these that can expand with the growing population to meet future needs may help secure the sustainable use of essential ecosystem services for the long term, improving the health of local people and maintaining the integrity of the forests in which they live.

\section{RÉSUMÉ}

Comprendre I'utilisation des ressources naturelles à Madagascar est essentiel pour développer des stratégies de conservation et de gestion plus larges qui permettent à la fois de fournir des services écosystémiques et de développer des stratégies sanitaires et économiques afin de répondre aux besoins d'une population humaine toujours croissante. Dans la forêt tropicale humide de basse altitude de Kianjavato dans le sud-est de Madagascar, 78\% des espèces de lémuriens, $83 \%$ des espèces de carnivores indigènes et $67 \%$ des espèces de chauves-souris frugivores sont menacés d'extinction. Ces trois groupes de mammifères sont généralement chassés dans d'autres régions de Madagascar, mais nous en savons peu sur les niveaux actuels de chasse ou si l'utili-

\footnotetext{
I Harvard T.H. Chan School of Public Health, Department of Environmental Health, 401 Park Drive, Boston, MA 02115, USA II MAHERY (Madagascar Health and Environmental Research), Maroantsetra 512, Madagascar

III Department of Anthropology, Montclair State University, 1 Normal Ave, Montclair, NJ 07043, USA

IV Department of Anthropology and Archaeology, University of Calgary, 2500 University Dr. NW, Calgary, AB T2N 1N4, Canada

V Grewcock Center for Conservation and Research, Omaha's Henry Doorly Zoo and Aquarium, 3701 S 10th St, Omaha, NE 68107, USA

VI Harvard University Center for the Environment, 26 Oxford St. 4th Floor, Cambridge, MA 02138, USA

Citation Borgerson, C., Johnson, S. E., Louis, E. E., Holmes, S. M., Anjaranirina, E. J. G., Randriamady, H. J. and Golden, C. D. 2018. The use of natural resources to improve household income, health, and nutrition within the forests of Kianjavato, Madagascar. Madagascar Conservation \& Development 13, 1: 45-52. http://dx.doi.org/10.4314/mcd.v13i1.6
} 


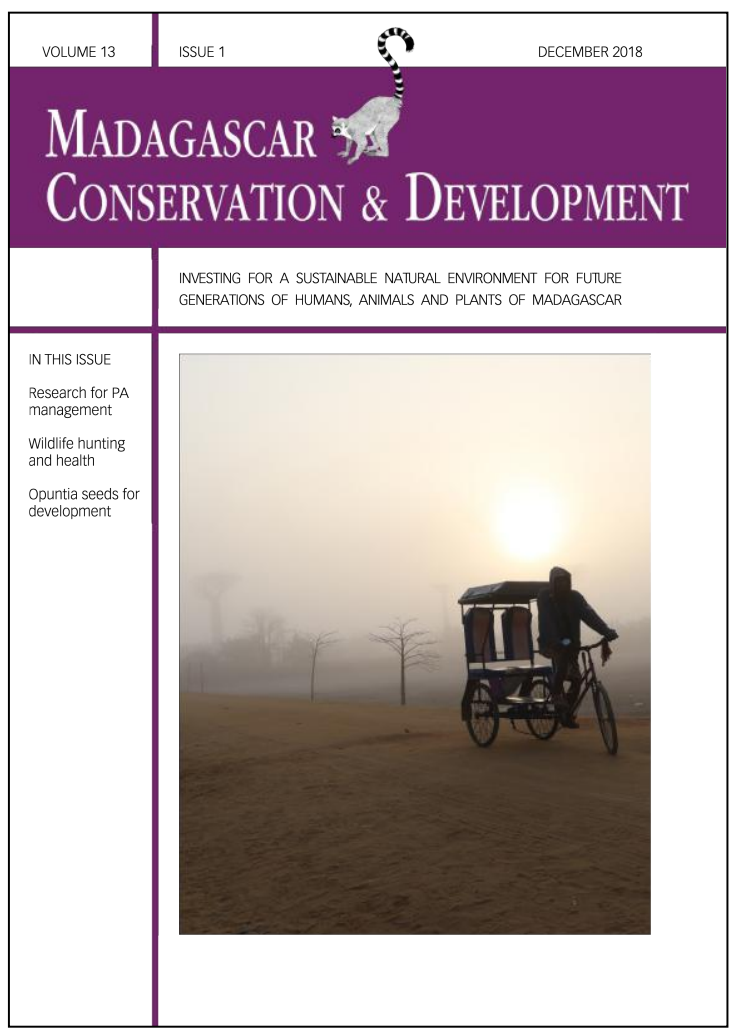

Madagascar Conservation \& Development is the journal of Indian Ocean e-Ink. It is produced under the responsibility of this institution. The views expressed in contributions to MCD are solely those of the authors and not those of the journal editors or the publisher.

All the Issues and articles are freely available at http://www.journalmcd.com

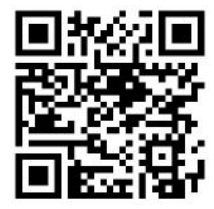

Contact Journal MCD

info@journalmcd.net for general inquiries regarding MCD funding@journalmcd.net to support the journal

Madagascar Conservation \& Development Institute and Museum of Anthropology

University of Zurich

Winterthurerstrasse 190

$\mathrm{CH}-8057$ Zurich

Switzerland

Indian Ocean e-Ink

Promoting African Publishing and Education

www.ioeink.com

Missouri Botanical Garden (MBG)

Madagascar Research and Conservation Program

Missouri Botanical Garden

BP 3391

Antananarivo, 101, Madagascar 
sation des ressources forestières affecte significativement le bienêtre humain dans cette région. Nous avons conduit une évaluation sanitaire sur 1267 habitants de Kianjavato, ainsi que des entretiens semi-structurés avec des membres de 336 ménages dans 17 communautés de Kianjavato afin d'étudier les interactions entre l'Homme et l'environnement. Nous avons constaté une forte prévalence de la malnutrition chez les enfants et les adolescents. Plus de la moitié de la population âgée de moins de 20 ans souffre d'un retard de croissance, plus de la moitié d'une insuffisance pondérale et plus d'un cinquième d'émaciation. En outre, un résident sur six est anémique. Nous avons constaté que les forêts de Kianjavato fournissent des services écosystémiques essentiels à ces communautés rurales. Comme les forêts de Kianjavato sont altérées pour répondre aux besoins d'une population croissante, ces services écosystémiques à usage direct (tels que la consommation d'animaux sauvages ou des plantes médicinales) ne peuvent plus couvrir les besoins fondamentaux des familles qui y vivent. Une proportion inquiétante de la population de Kianjavato dépend des forêts quant à ses besoins sanitaires, nutritionnels et économiques, cependant ces dernières ne peuvent plus y pourvoir entièrement. Tous les ménages enquêtés (100\%) comptent sur la forêt pour la satisfaction de leurs besoins sanitaires. Par ailleurs, I'exploitation de ressources forestières finies (extraction de pierres précieuses) représente $40 \%$ de l'économie régionale. La plupart des ménages consommaient très peu d'animaux sauvages (deux animaux par ménage par an) et la grande majorité (83\%) des animaux forestiers qu'ils mangeaient n'étaient pas menacés d'extinction. Cependant, $40 \%$ de ces animaux forestiers ont été capturés de manière illicite. Certes la chasse ne menace pas actuellement la faune locale mais $16 \%$ de la population de Kianjavato reconnait s'y adonner et $20 \%$ souffrent de malnutrition. Les services écosystémiques s'avèrent actuellement insuffisants pour répondre aux besoins des résidents. II est par conséquent nécessaire de cibler les efforts pour accroître l'accès local au système de santé, ensuite pour améliorer la nutrition et l'économie des ménages (améliorer la production et la stabilité des produits agricoles locaux), et tout ceci dans le but d'augmenter la viabilité à long terme de la chasse, des revenus et de la sécurité alimentaire dans cette région. De tels efforts lorsqu'ils prennent en compte la croissance de la population - et donc ses besoins futurs accrus - peuvent aider à assurer I'utilisation durable des services écosystémiques, à améliorer la santé des populations locales, et en fin de compte, à maintenir l'intégrité des forêts dans lesquelles elles vivent.

\section{INTRODUCTION}

Developing nations are working to find a balance between protecting their endemic biodiversity and providing for their growing human populations (Barrett et al. 2011). Madagascar's forests are a valuable resource for rural populations. They provide essential materials for housing (Kremen et al. 1999, Golden et al. 2014a, Borgerson et al. 2018), medicines for adequate healthcare (Rasoanaivo 1990, Rasoanaivo et al. 1992, Novy 1997, Norscia and Borgognini-Tarli 2006, Golden et al. 2012, Randriamiharisoa et al. 2015, Randrianarivony et al. 2017), and a source of food for a diverse diet (Kremen et al. 1998, Styger et al. 1999, Golden et al. 2011, Andriamparany et al. 2015, Borgerson et al. 2016, Golden et al. 2016) in places where adequate alternatives to these resources are often inaccessible, unaffordable, and/or unavailable in sufficient quantity. Government bodies and both public health and conservation NGOS have an opportunity to: (1) create broader management strategies that create positive incentives to promote the use of forest products at rates that remain within their ecologically sustainable limits; and (2) develop alternative health, economic, and food production strategies that can expand to meet the needs of a growing human population in ways that forest resources cannot. Such efforts may secure the integrity of forest ecosystem services for the long term-improving the health of local people and ecosystems for generations to come (Myers et al. 2013, Redford et al. 2014).

The Malagasy people will continue to coexist with and use their forests to support their livelihoods and foster their identity, their culture, and their spiritual systems (Keller 2009, Golden 2014). Yet many animal and plant resources have slow rates of reproduction and/or growth, and in the case of endemic lemurs, their future population viability depends on the survival of adults (Dunham et al. 2008, 2011, Godfrey and Rasoazanabary 2011). In these cases, over-extraction can contribute to reducing the population to levels that make them vulnerable to extirpation and eventual extinction. Previous research has focused on the use of forest resources surrounding Madagascar's national parks. Incentive and livelihood-based management strategies in the communities on Madagascar's national parks' borders have also been implemented with a primary goal of securing the ecosystem-focused management plans within park borders. However, most of Madagascar's people, and over $90 \%$ of Madagascar's land area, exist outside of these protected areas. Understanding the pressures of natural resource extraction outside of the national park system, and its impacts on local health and wellbeing, will be key to developing broader national level management strategies that ensure both the continued delivery of essential direct-use ecosystem services and the conservation of Madagascar's treasured native and endemic wildlife.

The Kianjavato forest of southeastern Madagascar is an area of lowland rainforest home to six species of endemic carnivorans, nine species of lemurs, and more species of bat (14) than any other eastern lowland site in Madagascar (MEFT 2008, Goodman et al. 2014). A portion of these forests fall within a mixed-use New Protected Area, the Forest Corridor Ambositra-Vondrozo (COFAV). Seventy-eight percent of Kianjavato's lemur species are threatened with extinction (two species are Critically Endangered; Prolemur simus and Varecia variegata), as are $83 \%$ of its native carnivoran species and $67 \%$ of its frugivorous bat species (IUCN 2016). All three of these groups of mammals are commonly hunted for food in other regions of Madagascar (Jones et al. 2008, Golden et al. 2011, 2014a,b, Jenkins et al. 2011, Borgerson 2015, 2016, Reuter et al. 2016a,b), yet we know little about current levels of hunting in this region or whether this exploitation has significant consequences for human welfare. Without an adequate understanding of the complex interactions between the people of the Kianjavato region and their natural environment, it will be difficult for local people, natural resource managers, and public health officials to prevent, mitigate, or adapt to future unwanted ecosystem changes.

Here, we present the results of a four-month assessment of communities in the Kianjavato region of Madagascar. We collected data concerning conservation-relevant human behaviors in order to understand the ways in which Kianjavato's forests provide resources that improve the wealth, health and nutrition of the Malagasy people who live in this region. It is our hope that these data 
aid public health and conservation specialists in creating broader data-based management strategies that both promote the sustainable use of forest resources, and develop alternative health, economic, and food production strategies that can expand to meet the needs of the people and ecosystems of Kianjavato.

\section{METHODS}

STUDY SITE. Kianjavato is within the Vatovavy-Fitovinany region of southeastern Madagascar. The Vatovavy-Fitovinany region is home to a primarily rural population of at least $1,104,675$ people (54.7 individuals per square kilometer) (MEFT 2008) mainly from the Antaimbahoaka ethnolinguistic group (this study). The principal economic activity of local people is agriculture, which is supplemented primarily by livestock raising, forestry, and fishing (MEFT 2008). Literacy is low, with only $41.5 \%$ of the adult population being able to read and write. Vatovavy-Fitovinany (the region comprising Kianjavato) has stronger transportation infrastructure compared to other remote eastern regions of Madagascar. The region can be accessed by a regional airport as well as by railway, three national highways and several large rivers (ibid).

The Vatovavy-Fitovinany ecosystem is characterized by wooded grasslands and pseudo-steppes (61.5\% of all land area), agricultural land (22.5\%), and forest lands (12.9\%) (MEFT 2008). Within this region, Kianjavato is a low elevation humid evergreen forest with an annual rainfall of $1,800 \mathrm{~mm}$ (FOFIFA weather station 2011, Manjaribe et al. 2013). The region is home to 105 plant species endemic to Madagascar (two are endemic to the region) and 220 nationally endemic animal species (nine are endemic to the region) (MEFT 2008). A portion of the Kianjavato forests fal within the COFAV protected area (IUCN Category VI), but all are subject to national laws regarding water and forest resource management. Both the Kianjavato Ahmanson Field Station (KAFS; operated by the Madagascar Biodiversity Partnership) and the Conservation Credit Program (which includes the Education Promoting Reforestation Project; Manjaribe et al. 2013) are working in the region to support research, forest conservation, and local livelihoods.

SURVEY PROTOCOLS. Between January and April 2014, we surveyed 336 households, including 1267 individuals, in 17 communities in the Kianjavato region. All surveys were completed by the MAHERY team, which is not involved in local natural resource management. We consulted with the local community leaders and then held a local community meeting to discuss the goals and possible implications of the project before beginning household interviews in each village. During the community meetings, the research was described as an effort to understand the ways in which natural resource use contributed to human health and general wellbeing.

We interviewed either the male or female head of each household to gather information on household demographics, agricultural labor, livestock raising and diseases, income generation, commercial good ownership, forest resource use, and hunting behavior. Commercial goods included shoes, bicycles, radios, watches, flashlights, and guns. In general, we asked interviewees to recall events over the prior year. Households randomization was conducted per methods in Borgerson et al. (2018). The head of each household consented to participate in the research survey. In addition to questions administered solely to the head of household, we also collected data on the health of all available in- dividuals in the surveyed households (1267 individuals within these 336 households). We recorded the sex, age (to the nearest whole year), occupation and educational obtainment of each household member. We then collected specific health information including anthropometric data (height and weight), a history of malaria episodes, a history of deworming medication, and a hemoglobin and blood oxygen level using a portable hemoglobinometer (Rainbow Pulse CO-oximeter from MASIMO) (644 individuals). This simple, non-invasive method uses photospectrometry rather than a blood sample to assess hemoglobin levels.

VARIABLE CREATION AND ANALYSIS. Simple summary statistics were calculated for most forms of environmental resource use and socio-demographic variables. Thresholds from the Center for Disease Control and Prevention (CDC) (2000) were used to calculate the prevalence of anemia from levels of hemoglobin in children and adults and the prevalence of stunting, underweight, and wasting (children $<5$ years old) or low BMl for age (children $>5$ years old) in children and young adults age 2-20. Children were defined as stunted, underweight, or wasted if their height-for-age, weight-for-age, weight-for-height, or BMl-for-age is more than two standard deviations below the CDC (2000) Child Growth Standards median. Children under 59 months were considered anemic if their hemoglobin values were less than 11.0, children who were between the ages of five and $12(5<12)$ were anemic considered anemic if their hemoglobin values were less 11.5 , children age 12 to $15(12<15)$ if less than 12.0 , women 15 years and older if less than 12.0, and men 15 years and older if less than 13.0. The fatality rates of diseases and illnesses afflicting livestock were calculated by dividing the number of animal deaths reported for a given disease over the prior year by the number reported to have been afflicted by that disease. To examine if endangered animals were more likely to be reported as eaten in another person's home (instead of hunted by the participant) we performed a Chi square on IUCN threatened status and hunting methods (both nominal categorical variables). We analyzed the relationship between wildlife consumption, child malnutrition, and hemoglobin levels using an established generalized linear mixed model where all individuals were clustered at the household level. Hemoglobin was an untransformed continuous outcome variable that controlled for the age and sex of the individual, wildlife consumption was a $\log _{10}+1$ transformed continuous explanatory variable, and household income ( $\log _{10}+1$ transformed) was controlled for as a continuous variable. Hemoglobin levels and the z-scores for child growth in this population were roughly normally distributed and did not require transformation.

\section{RESULTS}

The 336 surveyed households in the Kianjavato region were comprised of a mean of 3.77 individuals (median 3). Almost half of the population (47\%) was less than or equal to 16 years of age and $7 \%$ were under age two. Participants were primarily of the Antaimbahoaka ethnolinguistic group (66\%), followed by Betsileo (11\%), Merina (10\%), Tanala (9\%), and Tandroy (4\%).

HOUSEHOLD ECONOMY. All households reported farming as their primary employment. Forty-two percent of households declined to answer whether they had received cash income during the prior year. The preponderance of precious stone mining and sales (an often-illegal behavior) likely explains the high preva- 
lence of respondents declining to answer questions about income generation, a behavior we have not found common in other regions of Madagascar. Households that reported their cash income earned a median of 50,000 Malagasy Ariary (MGA) (US\$21.74) (mean of $411,740 \pm 708,938$ MGA or US $\$ 179.02 \pm$ US $\$ 308.23$ ) during the previous year or a median of 16,667 MGA per person (US\$7.22) (mean $148,903 \pm 365,299$ MGA or US\$64.74 \pm US\$158.83). One-tenth of households had sold amethysts, emeralds, corundum, or crystals during the prior year and the money earned from the sale of precious stones supplied $39.0 \%$ of all reported cash income (the highest percentage out of all reported income-earning categories). Of the households whose members had sold precious stones during the prior year, half had sold emeralds (providing $43.8 \%$ of total income from the sale of precious stones; with a median earning of 1,500,000 MGA per household), over a quarter (27.8\%) had sold corundum (34.4\% of precious stone income; median household earnings of 3,000,000 MGA), 16.7\% had sold amethysts (21.1\%; 3,000,000 MGA), and $5.6 \%$ had sold crystals $(0.6 \% ; 200,000 \mathrm{MGA})$.

Chickens were the most commonly owned domestic livestock, followed by ducks (Table 1). On average, adult chickens were sold in this region for 12,000 MGA (or US\$5.22). All households which owned chickens had some of their flock die from disease during the prior year. All deaths were reported to be caused by a disease locally referred to as barika. The symptoms of the disease were consistent with Newcastle disease and the estimated fatality rate was $31.0 \%$.

A minority of the Kianjavato population (13.0\%) made use of lasy, a seasonal home close to rice fields, during the prior year. For those residents that used lasy, this use peaked during April at the height of labor demands for swidden agriculture $(43.2 \%$ of all lasy were occupied during this time). The average lasy was a 3.75 \pm 2.10 hour walk from the center of the community with a maximum distance of 15 hours. Therefore, the average lasy was approximately $16.36 \mathrm{~km}$ away if we estimate time-distance relationships and expect normal walking speeds (Ralston 1958).

HEALTH. Malnutrition was a profound issue (Table 2). Of all measured households, $52.5 \%, 71.25 \%$, and $22.5 \%$ contained stunted, underweight, and wasted children, respectively. We found no significant differences between male and female children in their nutritional status. Nearly one in five (128 of 646) subjects was anemic. Men were significantly more likely to be anemic than

Table 1. The range and mean of household livestock assets in Kianjavato communities.

\begin{tabular}{llllll}
\hline Type of livestock & Cow & Pig & Duck & Chicken & Goose \\
\hline Range (\#/household) & $0-15$ & $0-14$ & $0-40$ & $0-70$ & $0-14$ \\
Mean (\#/household) & 1.28 & 0.43 & 3.79 & 8.02 & 0.53 \\
\hline
\end{tabular}

Table 2. Percentages of individuals categorized as stunted, underweight, wasted, or anemic in villages within the Kianjavato region. (* Sample sizes of children under five (one individual) and children 6-12 (11 individuals) are too small to report independently, so all ages of children under 20 have been collapsed into a single group for analysis. The finger-cuff used at this time to measure hemoglobin using photospectrometry was difficult to use on children with small fingers, and heights and weights were only recorded for individuals whose hemoglobin was measured. This issue has since been resolved. ** One individual whose hemoglobin was measured declined to have their weight or height measured.)

\begin{tabular}{llllll}
\hline Age range (yrs) & Sample size $(\mathrm{n})$ & Stunted & Underweight Wasted & Anemic \\
\hline $2-20^{\star}$ & 89 & $52.8 \%$ & $69.7 \%$ & $22.5 \%$ & $20.0 \%$ \\
$21-55$ & $486^{\star \star}$ & - & - & - & $19.6 \%$ \\
$>55$ & 69 & - & - & - & $21.7 \%$ \\
\hline
\end{tabular}

women ( $X^{2}$ : $D F=1$ (628), $R^{2}=0.03, p<0.0001 ; 54.30 \%$ of men (total number of men sampled $=341$ ) vs. $45.70 \%$ of women (total number of women sampled $=287)$ ).

NATURAL RESOURCE USE. Respondents reported a very high reliance on the forest for healthcare. Nearly all (99.7\%) households harvested traditional medicines from the forest at a median frequency of two times per week (mean of $2.20 \pm 0.83$ times), collected at a median distance of 30 minutes (mean of 47 \pm 140 minutes) from the home. Ninety-one percent of the population relied on firewood for cooking. Individuals walked a median of 30 minutes (mean of $46 \pm 94$ minutes) each day to collect firewood, and none of this wood was sold. None of the interviewees had collected honey during the prior year. Local people reported high bee mortality attributed to a pervasive disease. There were distinct gender roles in the collection of natural products. While the collection of traditional medicinal plants was predominantly a female activity (85.0\% of all collection was done by adult women), firewood was primarily collected by adult men in the household (83.0\% of collection).

Sixteen percent of households had consumed wildlife in the prior year (3.0\% had in the prior month). Of the 755 forest mammals that surveyed households consumed during the previous year, $46.0 \%$ were tenrecs, $31.5 \%$ were bats, $12.7 \%$ were lemurs, $6.6 \%$ were bushpigs, $2.9 \%$ were euplerids, and $0.3 \%$ were introduced carnivorans (Table 3.) Assuming the average un-processed weights of species (Goodman 2012), the surveyed households caught a total of 553 kilograms of meat during the prior year (median of $0 \mathrm{~kg}$ and mean $1.7 \pm 6.9 \mathrm{~kg}$ per household; range $0-58 \mathrm{~kg}$ ). Only $7.4 \%$ of households ate tenrec meat (these households each ate a median of six tenrecs or $6.6 \mathrm{~kg}$ of tenrec meat during the prior year), $5.7 \%$ of households ate lemurs (two lemurs; $1.26 \mathrm{~kg}$ ), $4.5 \%$ ate bats (five bats; $1.31 \mathrm{~kg}$ ), $4.2 \%$ ate the meat of bushpigs; and $2.1 \%$ ate carnivorans (one native euplerid and one introduced viverrid carnivoran; $8.0 \mathrm{~kg}$ ). Bushpig meat was often purchased in pieces weighing roughly $1-2 \mathrm{~kg}$ per piece. Of the $16.0 \%$ of households that reported eating wild meat during the prior year, they ate a median of six forest mammals (mean of $14.5 \pm 15.7$ ).

One out of every six forest mammals eaten during the prior year was threatened with extinction; $1.3 \%$ were Critically Endangered, $11.0 \%$ were Endangered, $5.2 \%$ were Vulnerable, $28.6 \%$ were Near Threatened, and 53.9\% were Least Concern (IUCN 2016). IUCN status did not significantly affect the number of animals that respondents reported eating in their own or another person's household. According to the most recent updates to legislation (Decree number 2006-400), at least $40.2 \%$ of hunting was conducted illegally either because of national prohibitions against hunting (e.g., lemurs) or prohibited equipment (e.g., hunting tenrecs using dogs). Individuals recalled their hunting over the prior year, and did not specify the calendar month in which they caught each animal. This prevents the identification of the illegal hunting of game species that were caught outside of their legal hunting season (i.e., tenrecs, euplerid carnivorans, and bats).

Approximately two percent of surveyed households owned a firearm (range 0-8 guns per household). Local Malagasy predominately reported eating wildlife at the households of friends and/or family (419 animals). This consumption was supplemented by targeted pursuit hunting (total of 153 animals) using nets (110), dogs (35), and thrown rocks (8). Opportunistic hunting (total of 118 animals) using found objects (97) and dogs (21) was also common. 
Table 3. The volume of mammalian wild life consumption in communities within Kianjavato, disaggregated by hunting method. (* IUCN (2016) CR, Critically Endangered; EN, Endangered; VU, Vulnerable; NT, Near Threatened; LC, Least Concern. ${ }^{\star \star P}$. larvatus was reported by the number of occasions this animal was consumed rather than the number of individuals, as it was frequently purchased as weighed pieces of meat (approx. 1-2kg) or eaten at friends' homes. The associated price is therefore also per piece and not per animal.)

\begin{tabular}{|c|c|c|c|c|c|c|c|c|c|c|}
\hline Species & Type of anima & N status* & $\begin{array}{l}\text { Hunting } \\
\text { regulations }\end{array}$ & $\begin{array}{c}\text { Total numbe } \\
\text { eaten }(n)\end{array}$ & $\begin{array}{c}\text { Eaten as a } \\
\text { guest (\%) }\end{array}$ & $\begin{array}{c}\text { Opportunistic } \\
\text { hunting (\%) }\end{array}$ & $\begin{array}{c}\text { Pursuit } \\
\text { hunting (\%) }\end{array}$ & Trapping & Purchased & $\begin{array}{c}\text { Price per } \\
\text { animal (MGA) }\end{array}$ \\
\hline Tenrec ecaudatus & Tenrec & LC & Seasonal & 282 & 58 & 24 & 12 & 0 & 6 & 1,824 \\
\hline Rousettus madagascariensis & Bat & NT & Seasonal & 216 & 46 & 0 & 53 & 0 & 1 & 1,000 \\
\hline Microcebus jollyae & Lemur & EN & Prohibited & 83 & 45 & 55 & 0 & 0 & 0 & - \\
\hline Setifer setosus & Tenrec & LC & Seasonal & 61 & 95 & 0 & 0 & 0 & 5 & 2,000 \\
\hline Potamochoerus larvatus** & Bushpig & LC & Unrestricted & 50 & 24 & 0 & 0 & 0 & 86 & $2,684^{* *}$ \\
\hline Pteropus rufus & Bat & VU & Seasonal & 22 & 41 & 23 & 36 & 0 & 0 & - \\
\hline Hapalemur griseus & Lemur & VU & Prohibited & 9 & 100 & 0 & 0 & 0 & 0 & - \\
\hline Fossa fossana & Carnivoran & VU & Seasonal & 6 & 100 & 0 & 0 & 0 & 0 & - \\
\hline Hemicentetes semispinosus & Tenrec & LC & Seasonal & 4 & 100 & 0 & 0 & 0 & 0 & - \\
\hline Galidictis fasciata & Carnivoran & VU & Seasonal & 4 & 100 & 0 & 0 & 0 & 0 & - \\
\hline Cheirogaleus major & Lemur & LC & Prohibited & 3 & 100 & 0 & 0 & 0 & 0 & - \\
\hline Varecia variegata & Lemur & CE & Prohibited & 2 & 100 & 0 & 0 & 0 & 0 & - \\
\hline Viverricula indica & Carnivoran & LC & Unrestricted & 2 & 100 & 0 & 0 & 0 & 0 & - \\
\hline Eulemur rufifrons & Lemur & NT & Prohibited & 1 & 100 & 0 & 0 & 0 & 0 & - \\
\hline Cryptoprocta ferox & Carnivoran & VU & Restricted & 1 & 100 & 0 & 0 & 0 & 0 & - \\
\hline $\begin{array}{l}\text { Daubentonia } \\
\text { madagascariensis }\end{array}$ & Lemur & EN & Prohibited & 0 & - & - & - & - & - & - \\
\hline Avahi peyrierasi & Lemur & VU & Prohibited & 0 & - & - & - & - & - & - \\
\hline Galidia elegans & Carnivoran & LC & Seasonal & 0 & - & - & - & - & - & - \\
\hline Total & & & & 755 & 55 & 16 & 21 & 0 & 8 & - \\
\hline
\end{tabular}

Purchasing wildlife (total of 60 animals) and trapping (total of five animals) was less common. Wildlife was purchased for a mean 7200 MGA (US\$3.13) per kilogram (range 1380-17,530 MGA per kilogram).

INTERACTIONS. Households that contained individuals who sold precious stones during the prior year earned significantly more than those that did not (T-test: $t=7.78, D F=18.34$, $p<0.0001 ; 1,821,111 \pm 831,737$ MGA (US $\$ 791.79 \pm$ US $\$ 361.62$ ) vs. $265,943 \pm 508,780$ MGA (US\$115.63 $\pm \$ 221.21)$ ). They also owned more commercial goods (T-test: $t=1.73, \quad D F=17.49, \quad p=0.05$; $5.75 \pm 7.10$ vs. $2.84 \pm 3.57$ ). Members of these households also ate more wild animals than those that did not sell stones (T-test: $t=2.30, D F=17.67, p=0.03 ; 8.89 \pm 7.57$ animals per household vs. $1.87 \pm 12.84)$. Specifically, they ate more bushpigs and lemurs (T-tests: $\mathrm{t}=1.68, \mathrm{DF}=17.37, \mathrm{p}=0.05 ; 0.89 \pm 1.97 \mathrm{~kg}$ of bushpig per household vs. $0.11 \pm 0.86 \mathrm{~kg}$, and $t=1.73, \mathrm{DF}=17.29, \mathrm{p}=0.05 ; 1.94$ \pm 4.21 lemurs per household vs. $0.22 \pm 1.64$ ) and fewer native carnivorans (euplerids) ( $t=-2.37, D F=317, p=0.02 ; 0.00 \pm 0.00$ euplerids per household vs. $0.04 \pm 0.28$ ). Household size and age demographics, the consumption of introduced carnivorans and bats, and the proportion of children that were categorized as stunted, underweight or wasted, were similar between households that did and did not sell precious stones during the prior year.

Household income seemed to be unrelated to participation in wild meat consumption and to the presence of wasted or anemic children in the household. Yet, households without stunted and underweight children had significantly higher incomes (T-test: $t=-$ 2.42, $D F=49.39, p=0.02,438,919 \pm 735,099$ MGA vs. 120,286 $\pm 341,140$ MGA per year; $t=-1.90, D F=24.30, p=0.04,531,682$ $\pm 866,319$ MGA vs. $168,333 \pm 386,504$ MGA per year). We did not find a relationship between wildlife consumption (the grams of forest mammal meat eaten by household members during the prior year) and anemia or stunting at this site. However, the amount of wildlife a household ate (in grams) was significantly positively correlated with child wasting and the severity of low body mass (generalized linear mixed model: $R 2=0.11, D F=2$, $F=5.56, p=0.005, R 2=0.11, D F=2, F=5.11, p=0.008$ ). Children were significantly more underweight and wasted within households that ate wild meat than in those that did not (T-tests: Weight $\mathrm{t}=-$ 2.19, $D F=26.31, p=0.04$, mean $z$-score $-4.33 \pm 3.63$ vs. $2.40 \pm 2.80$; Wasting $t=-2.37, D F=28.19, p=0.02$, mean z-score $-1.50 \pm 1.98 \mathrm{vs}$. $-0.34 \pm 1.70$ ). Because these data are cross-sectional, the tests are not designed to show a causal linkage. However, it is likely that inadequate access to food leads certain households to rely more heavily on wild meats.

\section{DISCUSSION}

We found that the communities surrounding Kianjavato's forests relied on natural resources for wealth, nutrition, and especially healthcare in a country where adequate alternatives to these resources are often inaccessible, unaffordable, and/or unavailable in sufficient quantity. The trade of precious stones was associated with higher household wealth, and greater wealth appeared to improve children's health and nutrition. However, these effects were perhaps unconnected: the children in households that traded stones were no healthier than those in households that did not sell these mineral resources. While members of households who sold precious stones were also more likely to eat wild meat, wild meat consumption was unrelated to household wealth. Perhaps the most striking finding was that nearly every household collected medicinal plants from the forest. Whether or not this activity positively affected health outcomes cannot be determined from our data, but its prevalence strongly suggests that these natural resources are important for community healthcare.

KIANJAVATO FORESTS AND HOUSEHOLD ECONOMY. The sale of amethysts, emeralds, corundum, and crystals supplied nearly $40 \%$ of all reported cash income during the prior year. Households that contained individuals who sold precious stones in the last year also ate nearly five times as many wild animals than those that did not. These findings differ from those in other regions of Madagascar, such as Alaotra, where people who were 
employed by a large-scale industrial nickel mine ate less wild meat than those who were not employed by the mine because of top-down incentives (Randriamamonjy et al. 2015). Formal industrial nickel mining in Alaotra was structured as a contractual engagement that benefitted the welfare and income of local residents with policies to prevent hunting, which led to either reduced consumption of wildlife or a significant fear of reporting it (Randriamamonjy et al. 2015). There are two commercial formal mining operations that employ local residents in the Kianjavato region. The mining reported by surveyed households in Kianjavato was not part of either commercialized formal activity, but rather an informal, artisanal and potentially illegal activity. It is possible that the interviewees in this study who were comfortable enough to report their open sale of high-value gemstones may also be more willing to report other sensitive information, such as the consumption of wildlife. It is also possible that informal gem collection at this site increased the amount of time spent in forests searching for these stones, allowing additional occasions for the opportunistic capture of wildlife, or increased income to facilitate the purchase of the comparatively expensive wild meat in the region.

KIANJAVATO FORESTS AND NUTRITION. Nearly one sixth of households in Kianjavato consumed forest meat during the prior year (16\%). The majority of the wildlife consumed was not threatened with extinction (83\%) but was often illegally caught (40\%). While this demonstrates broad non-compliance with conservation policies, illegal catch is less than that of the Alaotra wetland complex (Borgerson et al. 2018), the Makira Natural Park (Golden et al. 2014b), or Masoala National Park (Golden et al 2014b, Borgerson 2016, Borgerson et al. 2016) despite a general lack of law enforcement in the region (officials are often stationed far from the study area). Natural resource use in the forests of Kianjavato has notable similarities and differences from other areas in Madagascar. The people of Kianjavato ate less wildlife than those across other regions of Madagascar, including that of Moramanga, Port Berge, or Mahabo (Razafimanahaka et al. 2012), Betampona (Golden et al. 2014a), Masoala (Borgerson 2016), the Alaotra-Mangoro region (Jenkins et al. 2011), or sites across central and northwestern Madagascar (Reuter et al. 2016a), but ate more wildlife than those in the Alaotra wetland complex (Borgerson et al. 2018). Because we did not survey the density of wildlife in this study, we do not know what effect the availability of wildlife had on this consumption. However, within forest mammal groups, the percentages of households that consumed lemurs, carnivorans, bats, or bushpigs were within the ranges-albeit on the far lower end-of those found in other regions of Madagascar (Golden et al. 2013, 2014a,b, Reuter 2016a, Borgerson 2016, Borgerson et al. 2018).

One concerning finding was the consumption of the Critically Endangered lemur species, Prolemur simus. Assuming a minimum population size of 500 individuals (Wright et al. 2008, IUCN 2016), surveyed households ate as much as $1.6 \%$ of the remaining population during the prior year. These lemurs were eaten by a very small number of households $(\mathrm{N}=4)$, so small scale-targeted incentive-based conservation efforts may be particularly effective for this species.

As in other regions of Madagascar, tenrecs were the most common animal eaten in Kianjavato (Razafimanahaka et al. 2012, Golden et al. 2013, 2014a,b, Borgerson 2016, Reuter et al. 2016a).
However, the percentage of households that ate tenrecs during the prior year was smaller than any other documented region $7 \%$ in Kianjavato, compared to $10-91 \%$ in the sites across central and northeastern Madagascar, Alaotra, Betampona, Masoala, and Makira (ibid)).

Unlike other regions in Madagascar, local Malagasy reported eating the majority of wildlife when they were guests within the households of friends and family. We suspect people reported eating wildlife at the household of a friend or family member as a tool to provide accurate information to the interviewer without incriminating themselves. Most residents of Kianjavato (when not reporting eating wild animals as guests) preferred pursuit hunting using nets or opportunistic hunting using found objects. This also differs from other areas of Madagascar. Hunters in both Alaotra (Borgerson et al. 2018) and sites across central and northwestern Madagascar (Reuter et al. 2016b) primarily use pursuit hunting methods with dogs, whereas passive snare traps are predominantly used to trap forest mammals in Betampona, Makira, and Masoala (Golden et al. 2014a, Borgerson 2016).

While wildlife was rarely purchased (60 animals or $8 \%$ of all consumption), the percentage of wild meat purchased was higher than most other research sites in Madagascar (Golden et al. 2013, 2014a,b, Borgerson et al. 2018) but lower than in central and northwestern Madagascar (Reuter et al. 2016a). Wild meat was purchased at a price per kilogram far higher than that of Makira or Masoala in eastern Madagascar (Golden et al. 2014b) or that of sites across central and northwestern Madagascar (Reuter et al. 2016b); but prices were comparable to that of Mahabo in western Madagascar (Randrianandrianina et al. 2010).

Child malnourishment was more severe in Kianjavato than other sites in Madagascar: 53\% stunted, 70\% underweight, and $22 \%$ wasted (WHO 2012, rural Madagascar data). The prevalence of anemia was also high, with $20 \%$ of surveyed individuals being affected. Interestingly, we found no gender differences in the prevalence of stunting, underweight, and wasting in children, but found that males were significantly more likely to be anemic than females. The consumption of wild meat was correlated with child malnourishment within a household. Increasing the availability and affordability of nutrient-rich foods and promoting efforts that improve local food security may reduce the hunting of wild species, keeping it within sustainable limits (Wilkie et al. 2016). Previous research has shown that food insecurity can significantly increase the number of forest mammals a household eats (Borgerson et al. 2017, 2018) and that poor health can best predict a person's decision to illegally trap threatened lemurs (Borgerson et al. 2016). The subsistence consumption of forest animals can provide substantial economic and health benefits to Madagascar's rural poor (Golden et al. 2011, 2014a), which explains the psychology around this often-illegal behavior. Yet given the overall low levels of wild meat consumption at this site, and that the consumption of wild meat was not associated with lower childhood anemia or better growth at this site, the forests of Kianjavato may currently be unable to provide an adequate safety net for households experiencing malnutrition and food insecurity.

KIANJAVATO FORESTS AND HEALTHCARE. Ethnobotanical medicines can provide essential healthcare services for treatments that might otherwise be delayed or altogether avoided because of their prohibitive cost or inaccessibility (Golden et al. 2012, Pattanayak and Sills 2001). For example, in southwestern 
Madagascar 235 plant species are used to treat 76 categories of illness (Randrianarivony et al. 2017), and in northeastern Madagascar 241 plant species are used to treat 82 categories of illness, providing an economic benefit equivalent to $43-63 \%$ of annual household income (Golden et al. 2012). Kianjavato residents relied on forest resources for healthcare more than other regions of Madagascar and they travelled farther distances to reach these presumably valuable resources (Golden et al. 2012, Borgerson et al. 2018). Nearly $100 \%$ of households harvested traditional medicines from the forest (compared to $5 \%$ in Alaotra, $82 \%$ in Betampona, and $94 \%$ in Makira), at a rate of approximately twice as often as in Betampona and a distance twice as far from the home as in Alaotra (Golden et al. 2012, 2014b, Borgerson et al. 2018).

\section{CONCLUSIONS}

Forests provide essential ecosystem services that improve the wellbeing of the rural communities that live within them (Ickowitz et al. 2016, Milner-Gulland 2012, Redford et al. 2014, Rowland et al. 2017, Sunderland et al. 2013). Yet, as forests are altered to meet the needs of a growing human population, certain direct-use ecosystem services (such as the use of wild animals for food or plants for medicine) are unable to similarly expand to meet the basic needs of the families which live in these forests (Wilkie et al. 2016). A worrying proportion of the Kianjavato population hunts wildlife, is malnourished, and depends on forests to meet their healthcare needs, yet they may be failing to do so. The ecosystem services of Kianjavato's forests may currently be insufficient to meet the needs of residents. Therefore, targeted efforts to increase local access to the healthcare system, household nutrition, food security, and economy while restoring wide-scale environmental conditions are urgently needed. Efforts to improve the stability and accessibility of health, economic, and nutritional services, that can expand with the growing population to meet future needs, may help secure the sustainable use of the remaining essential ecosystem services for the long term, improving the health of local people and maintaining the integrity of the forests in which they live.

\section{ACKNOWLEDGEMENTS}

The warm welcome we received from all residents near Kianjavato is something our team will not soon forget-thank you for your hospitality. We received permits for our research from the Madagascar Ministry of Health No 253/MSANP/SG/DGS/DPLMT, the Harvard T.H. Chan School of Public Health's Institutional Review Board No 13-1862, and from the chef fokontany in each local community where we worked. We would like to thank Cynthia Frasier, Freddy Ranaivoarisoa, Susie Louis, Laurie R. Godfrey, and Hoby Rakotondramiarana for intellectual support and facilitating all of our work throughout the research period. CB and CDG acknowledge financial support from the National Science Foundation SBE-IBSS Postdoctoral Research Fellowship (grant 1513638). CDG would also like to thank the National Geographic Society Conservation Trust (grant C135-08) and the Margot Marsh Biodiversity Fund (grant 023815) for beginning our efforts to expand the work of the MAHERY team outside of Maroantsetra to explore the connections between natural resource exploitation, conservation governance and human health and livelihoods throughout Madagascar. Any researchers in Madagascar who would like to collaborate in this effort and share protocols and survey instruments are welcome to contact the authors.

\section{REFERENCES}

Andriamparany, J. N., Brinkmann, K., Wiehle, M., Jeannoda, V. and Buerkert, A. 2015. Modelling the distribution of four Dioscorea species on the Mahafaly Plateau of south-western Madagascar using biotic and abiotic variables. Agriculture, Ecosystems \& Environment 212, 20: 38-48. <https://doi.org/10.1016/j.agee.2015.06.019>

Barrett, C. B., Travis, A. J. and Dasgupta, P. 2011. On biodiversity conservation and poverty traps. Proceedings of the National Academy of Sciences of the United States of America 108, 34: 13907-13912. <https://doi.org/10.1073/pnas.1011521108>

Borgerson, C. 2015. The effects of illegal hunting and habitat on two sympatric endangered primates. International Journal of Primatology 36, 1: 74-93. <https://doi.org/10.1007/s10764-015-9812-x>

Borgerson, C. 2016. Optimizing conservation policy: The importance of seasonal variation in hunting and meat consumption on the Masoala peninsula of Madagascar. Oryx 50, 3: 405-418. <https://doi.org/10.1017/\$0030605315000307>

Borgerson, C., McKean, M. A., Sutherland, M. R. and Godfrey, L. R. 2016. Who hunts lemurs and why they hunt them. Biological Conservation 197: 124-130. <https://doi.org/10.1016/j.biocon.2016.02.012>

Borgerson, C., Rajaona, D., Razafindrapaoly, B., Rasolofoniaina, B. J. R., Kremen, C. and Golden, C. D. 2017. Links between food insecurity and the unsustainable hunting of wildlife in a UNESCO world heritage site in Madagascar. The Lancet 389: S3. <https://doi.org/10.1016/S0140-6736(17)31115-7>

Borgerson, C., Anjaranirina, E. J. G., Vonona, M. A., Vonona, T. and Golden, C. D. 2018. An evaluation of the interactions among wildlife hunting, human health, and household economies in the Lake Alaotra wetland complex of Madagascar. Madagascar Conservation \& Development 13, 1 . <https://doi.org/10.4314/mcd.v13i1.5>

Centers for Disease Control and Prevention. 2000. National Center for Health Statistics CDC growth charts, United States. $<$ https://www.cdc.gov/growthcharts/cdc_charts.htm>

Dunham, A. E., Erhart, E., Overdorff, D. J. and Wright, P. C. 2008. Evaluating effects of deforestation, hunting, and El Niño events on a threatened lemur. Biological Conservation 141, 1: 287-297. <https://doi.org/10.1016/j.biocon.2007.10.006>

Dunham, A. E., Erhart, E. and Wright, P. 2011. Global climate cycles and cyclones: Consequences for rainfall patterns and lemur reproduction in southeastern Madagascar. Global Change Biology 17, 1: 219-227. $<$ https://doi.org/10.1111/j.1365-2486.2010.02205.x>

Godfrey, L. R. and Rasoazanabary, E. 2011. Demise of the bet hedgers: A case study of human impacts on past and present lemurs of Madagascar. In: The Anthropology of Extinction: Essays on Culture and Species Death. G. M. Sodikoff (ed.), pp 165-199. Indiana University Press, Bloomington and Indianapolis, USA

Golden, C. D. 2014. Spiritual roots of the land: hierarchy and relationships of the religious cosmologies of humans and their environment in the Maroantsetra region of Madagascar. Worldviews: Global Religions, Culture, and Ecology 18, 3: 265-268. <https://doi.org/10.1163/15685357-01802010>

Golden, C. D., Fernald, L. C. H., Brashares, J. S., Rasolofoniaina, B. J. R. and Kremen, C. 2011. Benefits of wildlife consumption to child nutrition in a biodiversity hotspot. Proceedings of the National Academy of Sciences of the United States of America 108, 49: 19653-19656. <https://doi.org/10.1073/pnas.1112586108>

Golden, C. D., Rasolofoniaina, B. J. R., Anjaranirina, E. J. G., Nicolas, L., Ravaoliny, L. and Kremen, C. 2012. Rainforest pharmacopeia in Madagascar provides high value for current local and prospective global uses. PLOS ONE 7, 7: e41221. <https://doi.org/10.1371/journal.pone.0041221>

Golden, C. D., Wrangham, R. W. and Brashares, J. S. 2013. Assessing the accuracy of interviewed recall for rare, highly seasonal events: the case of wildlife consumption in Madagascar. Animal Conservation 16, 6: 597-603. <https://doi.org/10.1111/acv.12047>

Golden, C. D., Rabehatonina, J. G. C., Rakotosoa, A. and Moore, M. 2014a. Socioecological analysis of natural resource use in Betampona Strict Natural Reserve. Madagascar Conservation \& Development 9, 2: 83-89. <https://doi.org/10.4314/mcd.v9i2.4> 
Golden, C. D., Bonds, M. H., Brashares, J. S., Rasolofoniaina, B. J. R. and Kremen, C. 2014b. Economic valuation of subsistence harvest of wild life in Madagascar. Conservation Biology 28, 1: 234-243. <https://doi.org/10.1111/cobi.12174>

Golden, C. D., Gupta, A. C., Vaitla, B. and Myers, S. S. 2016. Ecosystem services and food security: assessing inequality at community, household and individual scales. Environmental Conservation 43, 4: 381-388. <https://doi.org/10.1017/S0376892916000163>

Goodman, S. M. 2012. Les Carnivores de Madagascar. Association Vahatra, Antananarivo, Madagascar.

Goodman, S. M., Rasoanoro, M., Ralisata, M. and Ramasindrazana, B. 2014. The bats of the Kianjavato-Vatovavy region, lowland eastern central Madagascar. Malagasy Nature 8: 89-102.

Ickowitz, A., Rowland, D., Powell, B., Salim, M. A., Sunderland, T. 2016. Forests, trees, and micronutrient-rich food consumption in Indonesia. PLOS ONE 11, 5: e0154139. <https://doi.org/10.1371/journal.pone.0154139>

IUCN. 2016. IUCN Red List of Threatened Species. <http://www.iucnredlist.org> accessed 25 May 2018.

Jenkins, R. K. B., Keane, A., Rakotoarivelo, A. R., Rakotomboavonjy, V., Randrianandrianina, F. H., et al. 2011. Rainforest pharmacopeia in Madagascar provides high value for current local and prospective global uses. PLOS ONE 7, 7: e41221. <https://doi.org/10.1371/journal.pone.0041221>

Jones, J. P. G., Andriamarovololona, M. M., Hockley, N., Gibbons, J. M. and MilnerGulland, E. J. 2008. Testing the use of interviews as a tool for monitoring trends in the harvesting of wild species. Journal of Applied Ecology 45, 4: 1205-1212. <https://doi.org/10.1111/j.1365-2664.2008.01487.x>

Keller, E. 2009. The danger of misunderstanding 'culture'. Madagascar Conservation \& Development. 4, 2: 82-85. <https://doi.org/10.4314/mcd.v4i2.48647>

Kremen, C., Raymond, I., Lance, K. 1998. An interdisciplinary tool for monitoring conservation impacts in Madagascar. Conservation Biology 12, 3: 549-563. <https://doi.org/10.1111/j.1523-1739.1998.96374.X>

Kremen, C., Razafimahatratra, V., Guillery, R. P., Rakotomalala, J., Weiss, A. and Ratsisompatrarivo, J.-S. 1999. Designing the Masoala National Park in Madagascar based on biological and socioeconomic data. Conservation Biology 13, 5: 1055-1068. <https://doi.org/10.1046/j.1523-1739.1999.98374.X>

Manjaribe, C., Frasier, C. L., Rakouth, B. and Louis, E. E. 2013. Ecological restoration and reforestation of fragmented forests in Kianjavato, Madagascar. International Journal of Ecology 2013: \#726275. $<$ https://doi.org/10.1155/2013/726275>

MEFT \& ONE (Ministère de L'Environnement, des Eaux et Forêts et du Tourisme \& Office National pour I'Environnement). 2008. Tableau de Bord Environmental; Région Vatovavy Fitovinany. Available at <https://www.pnae.mg/tbe/region-vatovavy-fitovinany.html>

Milner-Gulland, E. J. 2012. Interactions between human behaviour and ecological systems. Philosophical Transactions of the Royal Society B 367, 1586: 270-278. <https://doi.org/10.1098/rstb.2011.0175>

Myers, S. S., Gaffikin, L., Golden, C. D., Ostfeld, R. S., Redford, K. H., et al. 2013. Human health impacts of ecosystem alteration. Proceedings of the National Academy of Sciences of the United States of America 110, 47 : 18753-18760. <https://doi.org/10.1073/pnas.1218656110>

Norscia, I. and Borgognini-Tarli, S. M. 2006. Ethnobotanical reputation of plant species from two forests of Madagascar: A preliminary investigation. South African Journal of Botany 72, 4: 656-660. <https://doi.org/10.1016/j.sajb.2006.04.004>

Novy, J. W. 1997. Medicinal plants of the eastern region of Madagascar. Journal of Ethnopharmacology 55, 2: 119-126. <https://doi.org/10.1016/S0378-8741(96)01489-4>

Pattanayak, S. K. and Sills, E. O. 2001. Do tropical forests provide natural insurance? The microeconomics of non-timber forest product collection in the Brazilian Amazon. Land Economics 77, 4: 595-612. <https://doi.org/ 10.2307/3146943>

Ralston, H. J. 1958. Energy-speed relation and optimal speed during level walking. Internationale Zeitschrift für angewandte Physiologie einschliesslich Arbeitsphysiologie 17, 4: 277-283. <https://doi.org/10.1007/BF00698754>
Randriamamonjy, V. C., Keane, A., Razafimanahaka, H. J., Jenkins, R. K. B. and Jones, J. P. G. 2015. Consumption of bushmeat around a major mine, and matched communities, in Madagascar. Biological Conservation 186: 35-43. $<$ https://doi.org/10.1016/j.biocon.2015.02.033>

Randrianandrianina, F. H., Racey, P. A. and Jenkins, R. K. B. 2010. Hunting and consumption of mammals and birds by people in urban areas of western Madagascar. Oryx 44, 3: 411-415. <https://doi.org/10.1017/S003060531000044X>

Randrianarivony, T. N., Ramarosandratana, A. V., Andriamihajarivo, T. H., Rakotoarivony, F., Jeannoda, V. H., et al. 2017. The most used medicinal plants by communities in Mahaboboka, Amboronabo, Mikoboka, Southwestern Madagascar. Journal of Ethnobiology and Ethnomedicine 13: \#19. <https://doi.org/10.1186/s13002-017-0147-X>

Randriamiharisoa, M. N., Kuhlman, A. R., Jeannoda, V., Rabarison, H., Rakotoarivelo, N., et al. 2015. Medicinal plants sold in the markets of Antananarivo, Madagascar. Journal of Ethnobiology and Ethnomedicine 11: \#60. $<$ https://doi.org/10.1186/s13002-015-0046-y>

Rasoanaivo, P. 1990. Rain forests of Madagascar: sources of industrial and medicinal plants. Ambio 19, 8: 421-424.

Rasoanaivo, P., Petitjean, A., Ratsimamanga-Urveg, S. and Rakoto-Ratsimamanga, A. 1992. Medicinal plants used to treat malaria in Madagascar. Journal of Ethnopharmacology 37, 2: 117-127. <https://doi.org/10.1016/0378-8741(92)90070-8>

Razafimanahaka, J. H., Jenkins, R. K. B., Andriafidison, D., Randrianandrianina, F., Rakotomboavonjy, V., et al. 2012. Novel approach for quantifying illegal bushmeat consumption reveals high consumption of protected species in Madagascar. Oryx 46, 4: 584-592. <https://doi.org/10.1017/\$0030605312000579>

Redford, K. H., Myers, S. S., Ricketts, T. H. and Osofsky, S. A. 2014. Human health as a judicious conservation opportunity. Conservation Biology 28, 3: 627-629. $<$ https://doi.org/10.1111/cobi.12290>

Reuter, K. E., Randell, H., Wills, A. R., Janvier, T. E., Belalahy, T. R. and Sewall, B. J. 2016a. Capture, movement, trade, and consumption of mammals in Madagascar. PLOS ONE 11, 2: e0150305. <https://doi.org/10.1371/journal.pone.0150305>

Reuter, K. E., Randell, H., Wills, A. R. and Sewall, B. J. 2016b. The consumption of wild meat in Madagascar: drivers, popularity and food security. Environmental Conservation 43, 3: 287-283. <https://doi.org/10.1017/S0376892916000059>

Rowland, D., Ickowitz, A., Powell, B., Nasi, R. and Sunderland, T. 2017. Forest foods and healthy diets: quantifying the contributions. Environmental Conservation 44, 2: 102-114. <https://doi.org/10.1017/S0376892916000151>

Styger, E., Rakotoarimanana, J. E. M., Rabevohitra, R., Fernandes, E. C. M. 1999. Indigenous fruit trees of Madagascar: potential components of agroforestry systems to improve human nutrition and restore biological diversity. Agroforestry Systems 46, 3: 289-310. <https://doi.org/10.1023/A:1006295530509>

Sunderland, T., Abanda, F., de Camino, R. V., Matakala, F., May, P. H., et al. 2013. Sustainable forestry and food security and nutrition. Technical Report 11. CFS-HLPE/FAO. <http://www.fao.org/3/a-i7395e.pdf>

WHO (World Health Organization). 2012. WHO Global Database on Child Growth and Malnutrition, Madagascar. 13 January 2012. Available at $<$ https://goo.gl/1JsvCd>

Wilkie, D. S., Wieland, M., Boulet, H., Le Bel, S., van Vliet, N., et al. 2016. Eating and conserving bushmeat in Africa. African Journal of Ecology 54, 4: 402-414. $<$ https://doi.org/10.1111/aje.12392>

Wright, P. C., Johnson, S. E., Irwin, M. T., Jacobs, R., et al. 2008. The crisis of the Critically Endangered Greater bamboo lemur (Prolemur simus). Primate Conservation: 23: 5-17. <https://doi.org/10.1896/052.023.0102>

\section{SUPPLEMENTARY MATERIAL}

Figure S1. The Study Region.

S2. Survey Materials. 